\title{
Identification and Ranking of Factors in Successful Implementation of Knowledge Management in Eghtesad Novin Bank: an Ahp Approach
}

\author{
Mostafa Bahrami ${ }^{1}$, SuatOktar $^{2}$ \\ IPhD Student Banking and Insurance Institute, Marmara University, Istanbul, Turkey \\ 2 Professor of Banking and Insurance Institute, Marmara University, Istanbul, Turkey
}

\begin{abstract}
Many organizations focus on knowledge management and make huge investments in information technology. The purpose of this study was to identify and rank the driving factors in successful implementation of knowledge management in EghtesadNovin (EN) Bank of Iran using the AHP technique. 128 employees of the EN Bank participated in the study. Data were collectedusing a researcher-made questionnaire with a Cronbach's alpha of 0.873. AHP was used in Expert Choice to rank knowledge management success factors. The results indicated that strategy, senior management support, human resource management, organizational infrastructure, culture, incentives, administrative processes, and employee involvement were respectively the most important factors in successful implementation of knowledge management in EN Bank.
\end{abstract}

Keywords: Knowledge management, information technology, banks, AHP.

\section{Introduction}

Organizations of the new millennium are operating in a highly complex and fast-changing environment. To survive and compete, they must identify and adapt to these changes. The ensuing challenges have made organizations recognize the importance of knowledge, which enables them to respond to change, complexity, and uncertainty. Knowledge has become the key to survival and success and a major source of sustainable competitive advantage. It is also regarded as a strategic asset. In the past, the value of organizations was measured mainly based on their intangible assets, but today the intangibles are considered their most important assets.Knowledge management (KM) is crucial to exploiting and developing knowledge assets, and developing and implementing an effective knowledge management system (KMS) is one of the main goals of organizations. Many KM initiatives have failed, mainly due topoor understanding of KM and its components (Gallupe, 2001).Organizational knowledge is formed through unique patterns of interactions between technologies, techniques, and people. Exclusive focus on these components does not enable an organization to sustain its competitive advantages. It is, rather, the interaction them that allowsthe organization to manage its knowledge effectively. These interactionscannot be easily imitated by other organizations, as they are shaped by the organization's unique history and culture(Bhatti, 2002).

Various KM models have been proposed in the last few decades, the most widely used of which are Choo's (1998) Sense-Making KM Model and Conrad and Newman's (2000) General Knowledge Model. These models help organizations in their KM initiatives and provide a framework for effective creation, sharing, and use of knowledge.Choo (1998) asserts that the "knowing organizations" are those which use information strategically in the context of three arenas, i.e. sense making, knowledge creation and decision making.Conrad and Newman's (2000) General Knowledge Model organizes knowledge flows into four primary activity areas: knowledge creation, retention, transfer and utilization.Given the high rate of failure in KM projects, identifying KM success factors can help firms in their assessment, planning, and implementation. Satisfactory results in critical KM success factors ensure successful competitive performance and are the minimum key factors that an organization must have in order to achieve its goals (Alazami and Zairi, 2003).

Modern banks can significantly benefit from a well-developed and well-administered KMS. In the past banks seemed to be operating in a relatively stable, non-competitive environment, but today fast changes and uncertainty calls for faster and more dynamic responses in this industry. Although various models have been proposed for successful KM, little research has applied them to the banking industry. Thus, identification of KM success factors is of prime importance for banks, especially those in developing countries such as Iran, which are faced with problems such as employee underperformance and declining public investment. The purpose of the present research is to identify and rank KM success factors in the Iranian EghtesadNovin Bank using the AHP technique. 


\section{Literature Review}

Alavi and Leidner (2001) stressed the importance of cultural factors in KM success. Culture is defined as a set of values, beliefs, norms, meanings, and procedures shared by organization members (Robbin, 2004). Organizational culture shapes and guides the behavior of the organization's members and affects their response to different situations (Mavondo and Farrell, 2004). Each organization has a unique culture, which not only determines the type of knowledge that is created, but also its capacity for achieving competitive advantage. According to Alavi and Leidner (2001), successful KM lead to better decision-making, faster response time, improved productivity, and reduced costs. Therefore, a knowledge-oriented culture is a key KM enabler and can increase management commitment to undertaking KM initiatives.

De Long and Fahey (2000) studied the cultural barriers to knowledge management in more than 50 companies pursuing knowledge management projects. They found that, while, most managers intuitively recognize the importance of culture, they find it difficult to articulate the relationship of their existing culture to KM objectives. According to Ruppel and Harrington (2001), knowledge must be viewed as a process rather than an asset, because then the emphasis is on creating a proper environment to enable and facilitate the flow of information. They also suggested that people-based issues such as culture can be a potential barrier to effective implementation and use of knowledge.Similarly, Bhatt (2011) and Pauleen andMason (2002) reported cultural and management factors as the main potential barriers to successful KM implementation.McManus and Loughridge (2002) investigated the relationship between corporate information, institutional culture and knowledge management in UK university libraries. They found that culture and structure were major factors affecting perceptions of the relevance of knowledge management programs and projects. Davenport et al. (1998) have identified eight knowledge management success factors: technology infrastructure; organizational infrastructure; balance of flexibility, evolution, and ease-of-accessibility to knowledge; shared knowledge; knowledge-friendly culture; motivated workers who develop, share and use knowledge; means of knowledge transfer using various information technology infrastructure; and senior management support and commitment. Wong and Aspinwall(2005) identified 11 KM success factor: leadership and support; culture; information technology; strategy and purpose; measurement; organisational infrastructure; processes and activities; motivational aids; resources; training and education; and human resource management.Chourides et al. (2003), Mathi (2004), and Khalifa and Liu (2003) consider having strategy and purpose as a key factor in KM success. Moreover, Tiwana (2000) proposed four primary KM success factors: KM and business strategy alignment; knowledge map development; knowledge assets audit; and KM team design.

EidandNuhu (2011) examined the impact of learning culture and information technology use on knowledgesharing

in Saudi universities. They found a significant positive relationship between learning culture, IT use, and knowledge

sharing.

Kumar and Ganesh (2009) provided a morphology of the research literature on knowledge transfer in organizations. 8 dimensions were found suitable to characterize the knowledge transfer research literature: study, knowledge, agents, flow, mechanism, contextual factor, geography, and business context.

Asgari (2013) carried out a study to identify and rank the factors in implementation of knowledge management using the TOPSIS approach. A questionnaire was developed based on the model proposed by Bukowitz and Williams (Get, Use, Learn, Contribute, Assess, Build/Sustain, and Divest). The results showed all these factors affected KM implementation.

Huang and Lai (2012) examined the critical success factors for KM in the life insurance industry. Seven factors were identified: environments, individual characteristics, KM characteristics, organizational characteristics, IT infrastructure, cultural factor, and KM implementation. The results showed that: (1) environments significantly affect organizational characteristics; (2) environments and IT infrastructure significantly affect KM characteristics; and (3) individual characteristics, KM characteristics and organizational characteristics significantly influence KM implementation. Gonzalez and Martins (2014) studied on Mapping the organizational factors that support knowledge management in the Brazilian automotive industry .The results showedthat :the most important factors are respectively as follows: Human resources; teamwork; organizational culture; organizational structure; and development and absorption of knowledge. Bahrami et al. (2016) studied on Identification and Ranking of Factors in Successful Implementation of Knowledge Management in TürkiyeişBankasi: An AHP Approach . They identified $8 \mathrm{KM}$ success factor. The results showed that : the most important factors are respectively as follows: Strategy; senior management support; organizational infrastructure; incentives; human resource management; culture; administrative processes; and employee involvement. 


\section{Population and Sample}

\section{Methodology}

This research was a descriptive survey, covering the first half of 2015. The population consisted of all the branches of EghtesadNovin (EN) Bank in Tehran $(\mathrm{N}=90)$. Using cluster sampling, 4 employees (with the highest experience and academic degree) were selected from 8 branches in each of the 4 regions of the city $($ sample size $=128)$.

\section{Instrument}

Data were collected using a questionnaire that consisted of two section. The first section recorded the demographic data (i.e. gender, position, experience, and education). The second section included a paired comparison part for the identified factors (i.e. strategy, senior management support, organizational infrastructure, incentives, human resource management, culture, and administrative processes) and a part where the components of each factor were compared pairwise. This questionnaire is developed to identify and rank the factors in successful implementation of KM in EN Bank. It uses the AHP technique which is based on pairwise comparisons. Face validity of the instrument was evaluated by a panel of experts and the questionnaire was modified based on their comments. Cronbach's alpha was used to examine its reliability. The questionnaire was distributed among 30 randomly selected employees from each bank and the data were analyzed in SPSS. An alpha of 0.873 was obtained, indicating the reliability of the instrument. The analytic hierarchy process (AHP) was used as a multi-criteria decision-making method. AHP is one of the most effective techniques for organizing and analyzing complex decisions. It was developed by Thomas L. Saaty in the 1970s and is based on pairwise comparisons. Since the views of bank employees are not similar and are a function of various factors such as experience, position, and education, a weight was assigned to their responses: a weight of 1 for experience, a weight of 2 for education, and a weight of 3 for position.

\section{Findings}

Figure 1 shows the ranking of KM success factors in EN bank. According to the respondents, strategy is the most important factor $(\mathrm{W}=0.218)$, followed by senior management support $(\mathrm{W}=0.186)$, human resource management $(\mathrm{W}=0.154)$, organizational infrastructure $(\mathrm{W}=0.129)$, culture $(\mathrm{W}=0.102)$, incentives $(\mathrm{W}=$ $0.087)$, administrative processes $(\mathrm{W}=0.081)$, and employee involvement $(\mathrm{W}=0.043)$.

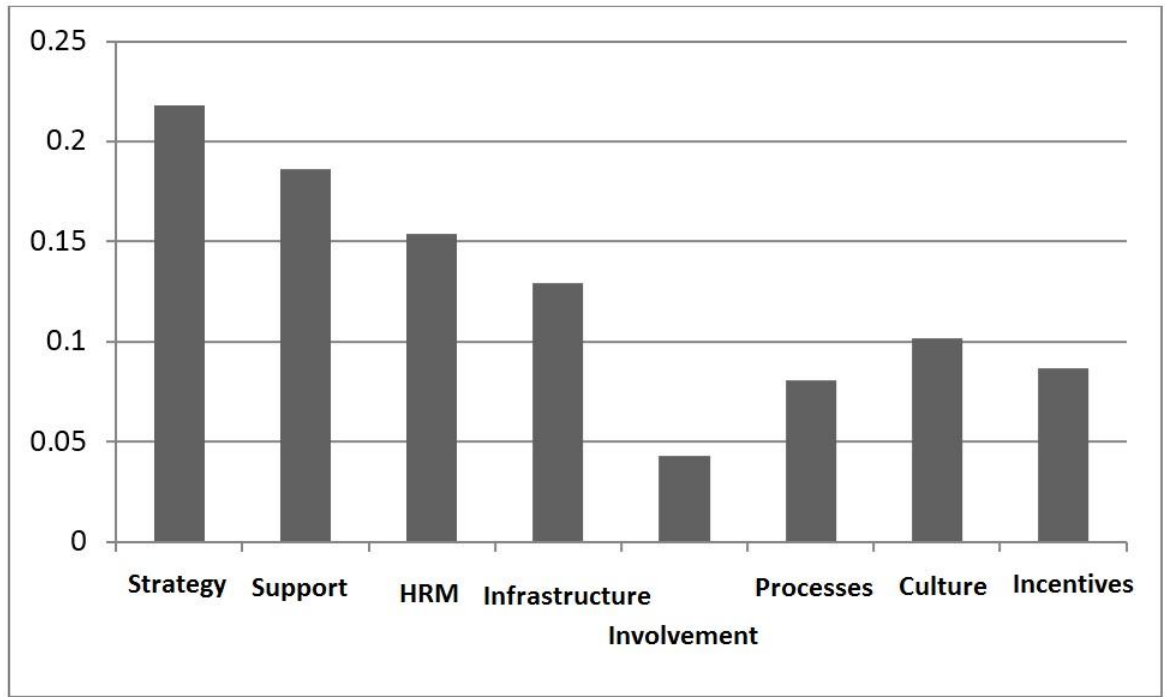

Figure 1. Prioritization of KM success factors in EN Bank

The incompatibility rate $\left(\lambda_{\max } W\right)$ is calculated based on the following steps:

Step 1. Estimating $\lambda_{\max } W:\left[\begin{array}{ccccc}1 & 3.55 & 2.72 & 2.8 & 1.92 \\ 0.28 & 1 & 1.1 & 1.1 & 1 \\ 0.37 & 0.91 & 1 & 1.2 & 1 \\ 0.36 & 0.91 & 0.83 & 1 & 1.22 \\ 0.52 & 1 & 1 & 0.82 & 1\end{array}\right] \times\left[\begin{array}{l}0.407 \\ 0.169 \\ 0.156 \\ 0.138 \\ 0.130\end{array}\right]=\left[\begin{array}{l}2.07 \\ 0.74 \\ 0.64 \\ 0.73 \\ 0.78\end{array}\right]$ 
Step 2. Calculating $\lambda_{\max }$ :

$$
\begin{aligned}
\lambda_{\max 1} & =\frac{2.07}{0.407}=5.09 \\
\lambda_{\max 2} & =\frac{0.74}{0.169}=4.38 \\
\lambda_{\max 3} & =\frac{0.64}{0.156}=4.1 \\
\lambda_{\max 4} & =\frac{0.73}{0.138}=5.29 \\
\lambda_{\max 5} & =\frac{0.78}{0.13}=6
\end{aligned}
$$

Step 3. Calculating mean $\lambda_{\max }$ :

$$
\frac{\lambda_{\max 1}+\cdots+\lambda_{\max 5}}{5} \rightarrow \frac{5.09+4.38+4.1+5.29+6}{5}=4.97
$$

Step 4. Calculating incompatibility index (II):

$$
I I=\frac{\lambda_{\max }-n}{n-1} \rightarrow \frac{4.97-5}{5-1}=\frac{-0.03}{4}=0.0075
$$

Step 5. Calculating incompatibility index $(I R)$ :

$$
I R=\frac{I \cdot I .}{I \cdot I \cdot R \cdot 5 \times 5} \rightarrow \frac{0.008}{1.12}=0.001
$$

The incompatibility rate is less than 0.01 , indicating the consistency of the responses. Incompatibility rates higher than 0.1 suggest that the paired comparisons must be reconsidered.

In terms of the components of each factor, the results were as follows:

- Strategy: The most important component was strategy and purpose $(\mathrm{W}=0.482)$, followed by strategic focus $(\mathrm{W}=0.308)$ and strategy alignment $(\mathrm{W}=0.210)$.

- Senior management support: The sponsor role of senior management was the most important component $(\mathrm{W}=0.517)$, followed by the initiator role $(\mathrm{W}=0.384)$ and the promoter role $(\mathrm{W}=0.099)$.

- Human resource development: The most important component was development opportunities $(\mathrm{W}=$ 0.397), followed byemployee retention $(\mathrm{W}=0.304)$ and knowledge sharing culture $(0.299)$.

- Organizational infrastructure: The most important component was clear roles and tasks $(\mathrm{W}=0.579)$, followed by knowledge leadership (0.354) and teamwork (0.067).

- Employee involvement: The most important factor wasKM capability $(\mathrm{W}=0.427)$, followed by employee skills $(\mathrm{W}=0.351)$ and technical capability $(\mathrm{W}=0.222)$.

- Administrative processes:Knowledge discovery was the most important factor $(\mathrm{W}=0.392)$, followed by knowledge sharing $(\mathrm{W}=0.360)$, documentation $(\mathrm{W}=0.275)$, and product/service knowledge $(\mathrm{W}=0.155)$.

- Culture: Trust was the most important factor $(\mathrm{W}=0.594)$, followed by cooperation $(\mathrm{W}=0.203)$, empowerment $(\mathrm{W}=0.104)$, and knowledge transfer $(\mathrm{W}=0.099)$.

- Incentives: The most important factor was tangible reward $(\mathrm{W}=0.491)$, followed byperformance evaluation $(\mathrm{W}=0.398)$ and group-based reward $(\mathrm{W}=0.111)$.

Finally, a consolidated matrix was created from the scores of all the factors and components, and the components were ranked. Table 1 shows that strategy and purpose have the greatest effect on KM success in EN Bank.

Table 1. Ranking of factors and components along with their relative weights

\begin{tabular}{|l|l|l|l|l|l|}
\hline Factor & Factor Wight & Component & Group Weight & Final Weight & Rank \\
\hline \multirow{3}{*}{ Strategy } & 0.218 & Strategic focus & 0.308 & 0.091 & 3 \\
\cline { 3 - 6 } & & Strategy and purpose & 0.482 & 0.123 & 1 \\
\cline { 3 - 7 } & & Strategy alignment & 0.210 & 0.071 & 5 \\
\hline Senior management support & \multirow{2}{*}{0.186} & Initiator & 0.384 & 0.088 & 4 \\
\cline { 3 - 7 } & & Promoter & 0.099 & 0.039 & 11 \\
\cline { 3 - 7 } & & Sponsor & 0.097 & 0.050 & 9 \\
\hline Human resource management & 0.154 & Knowledge sharing culture & 0.299 & & \\
\hline
\end{tabular}




\begin{tabular}{|c|c|c|c|c|c|}
\hline & & Employee retention & 0.304 & 0.057 & 7 \\
\hline & & Development opportunities & 0.397 & 0.059 & 6 \\
\hline \multirow[t]{3}{*}{ Organizational infrastructure } & \multirow[t]{3}{*}{0.129} & Knowledge leadership & 0.354 & 0.042 & 10 \\
\hline & & Teamwork & 0.067 & 0.029 & 15 \\
\hline & & Clear roles and tasks & 0.579 & 0.056 & 8 \\
\hline \multirow[t]{3}{*}{ Employee involvement } & \multirow[t]{3}{*}{0.043} & Skills & 0.351 & 0.004 & 23 \\
\hline & & Technical capability & 0.222 & 0.001 & 26 \\
\hline & & KM capability & 0.427 & 0.005 & 22 \\
\hline \multirow[t]{4}{*}{ Administrative processes } & \multirow[t]{4}{*}{0.081} & Documentation & 0.275 & 0.010 & 20 \\
\hline & & Knowledge discovery & 0.392 & 0.013 & 18 \\
\hline & & Knowledge sharing & 0.360 & 0.011 & 19 \\
\hline & & Product/service knowledge & 0.155 & 0.003 & 24 \\
\hline \multirow[t]{4}{*}{ Culture } & \multirow[t]{4}{*}{0.102} & Trust & 0.594 & 0.035 & 12 \\
\hline & & Cooperation & 0.203 & 0.034 & 13 \\
\hline & & Empowerment & 0.104 & 0.032 & 14 \\
\hline & & Knowledge transfer & 0.099 & 0.002 & 25 \\
\hline \multirow[t]{3}{*}{ Incentives } & & Tangible reward & 0.491 & 0.027 & 16 \\
\hline & & Group-based reward & 0.111 & 0.007 & 21 \\
\hline & & Performance evaluation & 0.398 & 0.021 & 17 \\
\hline
\end{tabular}

\section{Discussion and Conclusion}

The purpose of this research was to identify and rank the most important KM success factors in EghtesadNovin (EN) Bank using the AHP technique. The results showed that the most important success factors were: (1) strategy ( $\mathrm{W}=0.218)$, (2) senior management support $(\mathrm{W}=0.186)$, (3) human resource management $(\mathrm{W}=154),(4)$ organizational structure $(\mathrm{W}=0.129)$, (5) culture $(\mathrm{W}=0.102),(6)$ incentives $(\mathrm{W}=0.087),(7)$ administrative processes $(0.081)$, and (8) employee involvement (0.043). Our findings are consistent with the results of Alavi and Leidner (2001), Abbasi (2007), Rahnavard and Mohammadi (2009), Ardakani and Konjkav (2011), Haj Karimi and Mansourian (2012), Shabani et al. (2012), Salehi et al. (2012),Huang and Lai (2012),Asgari (2013),Gonzalez and Martins (2014) andbahrami\& et al (2016).all of whom examined somewhat similar KM success factors in various settings.

The order of the components was as follows: strategy and purpose, sponsor role, strategic focus, initiator role, strategy alignment, development opportunities, employee retention, clear roles and tasks, knowledge sharing culture, knowledge leadership, promoter role, trust, cooperation, empowerment, teamwork, tangible reward, performance evaluation, knowledge discovery, knowledge sharing, documentation, groupbased reward, KM capability, skills, product/service knowledge, knowledge transfer, and technical capability. This shows that the strategy and purpose component has the greatest effect on KM success in EghtesadNovin Bank. This is consistent with the results of Salehi (2012).

Overall, the results indicate that the identified factors affect KM success in the studied banks, albeit to varying degrees. The following recommendations can help KM success in EN Bank:

1. Well-defined strategy and purpose are critical for KM success. In addition, knowledge-based environment and knowledge-based networking are essential factors for banks.

2. Lack of strategy in knowledge creation and sharing, ineffective use of knowledge, or getting involved in activities that are not knowledge-based can have a negative impact on the performance of banks. Therefore, it is imperative to promote the use and benefits of KM and undertake KM initiatives.

3. Bank presidents and vice presidents must effectively perform their role in initiating, promoting, and sponsoring KM.

4. Banks must incorporate KM strategies into their business strategy and ensure their alignment in order to successfully deploy KMS.

5. Necessary investments must be made in building KM infrastructure.

This paper is taken from the doctoral dissertation of Mostafa Bahrami, titled "Investigation of Effecting Factors in Successful of Knowledge Management in Banks: ( The Case of TURKEY-IRAN Private Banks)”. Mostafa Bahrami. PhD Student, Banking and Insurance Institute, Marmara University, Istanbul, Turkey.

\section{References}

[1]. ABBASI, Z., 2007. "A review of knowledge management models. In Proceedings of the 1st National Conference on Knowledge Management", Razi International Conference Center.

[2]. $\quad$ ALAVI, M., LEIDNER, D. E., 2001." Review: Knowledge management and knowledge management systems: Conceptual foundations and research issues". MIS Quarterly, 25, 107-136.

[3]. $\quad$ ALAZAMI, M., ZAIRI, M., 2003." Knowledge management critical success factors".Total Quality Management, 14, 199-204.

[4]. ARDAKANI, S., KONJKAV, A. R., 2011. "Knowledge management success factors in higher education: A case of Yazd University". Iranian Journal of Business Management Research, 5, 136-158.

[5]. $\quad$ ASGARI, M. H., 2013." Identification and ranking of factors affecting the implementation of knowledge management based on TOPSIS technique". International Research Journal of Applied and Basic Sciences, 4, 3076-3084. 
[6]. Bahrami, M., Oktar, S., Karimpour, H., 2016. Identification and Ranking of Factors in Successful Implementation of Knowledge Management in TürkiyeișBankası: An AHP Approach. Advances in Applied Science Research, 7, 193-199.

[7]. BHATT, G. F., 2001." Knowledge management in organizations: Examining the interaction between technologies, techniques, and people".Journal of Knowledge Management, 5, 68-75.

[8]. CHOO, C., 1998. The Knowing Organization: How Organizations Use Information for Construct Meaning, Create Knowledge and Make Decisions. New York: Oxford Press.

[9]. CHOURIDES, P., LONGBOTTOM, D., MURPHY, W., 2003. "Excellence in knowledge management: An empirical study to identify critical factors and performance measures". Measuring Business Excellence, 7, 29-45.

[10]. DE LONG, D.W., FAHEY, L., 2000." Diagnosing cultural barriers to knowledge management".Academyof Management Executive, 14, 113-127.

[11]. [6] Eid, M., Nuhu, N.A., 2011. Knowledge Management Research \& Practice, 9, 48-57.

[12]. GALLUPE, B., 2001. "Knowledge management systems: Surveying the landscape". International Journal of Management Review, 3, 61-77.

[13]. Gonzalez, R. V. D., Martins, M. F., 2014. Mapping the organizational factors that support knowledge management in the Brazilian automotive industry. Journal of Knowledge Management, 18, 152-176.

[14]. Huang, L. S., Lai, C. P., 2012. An investigation on critical success factors for knowledge management using structural equation modeling. Procedia-Social and Behavioral Sciences, 40, 24-30.

[15]. HAJ KARIMI, A., MANSOURIAN, T., 2012. "The role of customer knowledge management in improving organizational performance". Iranian Journal of Business Management Research, 4, 75-92.

[16]. KHALIFA, M., Liu, V., 2003. "Determinants of successful knowledge management programs". Electronic Journal on Knowledge Management, 1, 103-112.

[17]. MATHI, K., 2004. "Key Success Factors for Knowledge Management". Lindau, Germany, MBA: International Business Management\& Consulting.

[18]. MCMANUS, D., LOUGHRIDGE, B., 2002."Corporate information, institutional culture and knowledge management: a UK university library perspective".New Library World, 103, 320-327.

[19]. MAVONDO, F., FARRELL, M., 2004. "Cultural orientation: Its relationship with market orientation, innovation and organisational performance". Management Decision, 41, 241-249.

[20]. NEWMAN, B. D., CONRAD, K. W., 2000." A framework for characterizing knowledge management methods, practices, and technologies". In: 3rd International Conference onPractical Aspects of Knowledge Management (PAKM2000) Conference, Basel, Switzerland, pp. 30-31 Oct.

[21]. Kumar, J. A., Ganesh, L. S., 2009. Research on knowledge transfer in organizations: A morphology. Journal of Knowledge Management, 13, 161-174.

[22]. Asgari, M. H., 2013. Identification and ranking of factors affecting the implementation of knowledge management based on TOPSIS technique. International Research Journal of Applied and Basic Sciences, 4, 3076-3084.

[23]. PAULEEN, D., MASON, D., 2002. New Zealand knowledge management survey: Barriers and drivers of KM uptake. Available athttp://www.nzkm.net/mainsite/ NewZealandKnowledgeManagementSurveyBarriersandDriv.html.

[24]. RAHNAVARD, F., MOHAMMADI, A., 2009." Identification of key knowledge management success factors in academia". Iranian Journal of IT Management, 1, 37-52.

[25]. ROBBIN, S. P., 2004. "Organizational Behavior". 11th ed. Upper Saddle River, NJ: Prentice- Hall.

[26]. RUPPEL, C. P., HARRINGTON, S. J., 2001. "Sharing knowledge through intranets: A study of organizational culture and intranet implementation".IEEE Transactions on Professional Communication, 44, 37-52.

[27]. SALEHI, M., RAJABI, R., BAHRAMI, M., 2012. "Factors in successful implementation of knowledge management: An AHP approach". In Proceedings of the 4th International Conference on Human Capital, Zanjan, 2012.

[28]. SHABANI, A., MOHAMMADI, M., FORUGOZAR, H., 2012. "Identification and ranking of factors in successful implementation of knowledge management using TOPSIS: A case of Shiraz University of Medical Sciences". Iranian Journal of Health Information Management, 9, 318-326.

[29]. TIWANA, A., 2000. "The Knowledge Management Toolkit: Practical Techniques for Building a Knowledge Management System". New Jersey: Prentice-Hall.

[30]. WONG, K.Y.,ASPINWALL, E., 2005. "An empirical study of the important factors for knowledge-management adoption in the SME sector". Journal of Knowledge Management, 9, 64-82. 